\title{
Characterization of Carbon-Coated ZnO Composite Powders Produced by Polymer Pyrolysis Method
}

\author{
Burak ÖZKAL, ${ }^{*, * *}$ Wei JIANG, ${ }^{*}$ Sumio KATO, ${ }^{* * *}$ Osamu YAMAMOTO* and Zenbe-e NAKAGAWA* \\ ${ }^{*}$ Research Institute of Materials and Resources, Faculty of Engineering and Resource Science, Akita University, \\ 1-1, Tegata, Gakuen-machi, Akita-shi 010-8502 \\ ${ }^{* *}$ Metallurgical \& Materials Engineering Department, Istanbul Technical University, 34469 Maslak, Istanbul, Turkey \\ ***Department of Materials-Process Engineering and Applied Chemistry for Environments, Faculty of Engineering and Resource Science, \\ Akita University, 1-1, Tegata, Gakuen-machi, Akita-shi 010-8502
}

\author{
ポリマー熱分解法により得られた炭素被覆 ZnO 複合体のキャラクタリゼーション \\ Burak Özkal ${ }^{* * * *} \cdot$ Wei Jiang* · 加藤純雄*** $\cdot$ 山本 修* · 中川善兵衛* \\ *秋田大学工学資源学部附属素材資源システム研究施設, 010-8502 秋田市手形学園町 1-1 \\ **Metallurgical \& Materials Engineering Department, Istanbul Technical University, 34469 Maslak, Istanbul, Turkey \\ ***秋田大学工学資源学部環境物質工学科, 010-8502 秋田市手形学園町 1-1
}

\begin{abstract}
In this study, carbon-coated $\mathrm{ZnO}$ powders were prepared via polymer pyrolysis method, polymer being used as poly (vinyl alcohol) and poly (vinyl chloride). Initial conditions, Type of polymer as carbon sources and particle-particle distance during the coating operation, were located as important parameters which directly affect the high quality of carbon-coated $\mathrm{ZnO}$ powders. After coating, morphologies and crystal structure of the carbon-coated samples were characterized by scanning electron microscope (SEM), transmission electron microscope (TEM), X-ray diffraction (XRD) and specific surface area measurement (BET). From BET data, the increase in specific surface area was observed after coating, irrespective of carbon source. The reason why the specific surface area increased after coating was based on nanoporous formation in the carbon film coated on the surface of powder. By TEM observation, it was found that nano-structure of carbon prepared from poly (vinyl alcohol) was different from that obtained from poly (vinyl chloride).
\end{abstract}

[Received September 16, 2004; Accepted November 26, 2004]

Key-words : Carbon, ZnO, Powder, Pyrolysis, Coating

1. Introduction

In recent years, many researches have been focused to produce composite or coated powders to bring together some unique advantages of two or more components into one small composite body. ${ }^{1)-4)}$ Preparation of carbon-coated ceramic powders is also one of the interesting efforts in this field. It is well known that carbon films can be produced from carboncontaining gas phases by physical vapor deposition (PVD) and hydrocarbon containing gases by chemical vapor deposition (CVD), and both processes described above have been applied on bulk substrates easily. ${ }^{5)-9)}$ Alternatively, during the pyrolysis of polymers (such as PVC and PVA) in inert atmosphere, some carbon remained as residue in the system. ${ }^{10), 11)}$ Since liquid phase with a low viscosity forms during pyrolysis, it is possible for neighbor surfaces to be wetted and coated by this liquid. By using this simple polymer mixing method, carbon coating of several ceramic powders have been announced. ${ }^{12)-16)}$ Production of carbon coated composite powders by such a simple and economical process is supposed to develop new candidate materials for certain applications where nanoporous carbon structure offers unique advantages. In the present work $\mathrm{ZnO}$ system was selected for potential utilization in the field of antibacterial ceramics. Although $\mathrm{ZnO}$ shows strong antibacterial activity without the presence of light, improvement is necessary against its easy dissolution reaction. It is thought that nanoporous carbon coating of $\mathrm{ZnO}$ powders will improve the easy dissolution behavior. However, formation and morphology of the carbon coating by polymer pyrolysis method are very important for the final properties and were not characterized in detail so far.
Therefore, in present work, carbon coating of $\mathrm{ZnO}$ powders were realized as a function of initial $\mathrm{ZnO}$ powder properties, carbon source; poly (vinyl alcohol) (hereafter, PVA) or poly (vinyl chloride) (hereafter, PVC) for the pyrolysis and physical distance to be coated $\mathrm{ZnO}$ particles during pyrolysis. Carbon-coated samples were characterized to find out more information on properties and structure of carbon residue which remains in the system.

\section{Experimental}

Two kinds of $\mathrm{ZnO}$ powders ( $\mathrm{ZnO}-\mathrm{I}$, purity $99.95 \%$ and ZnO-II, purity 99\%, Kanto Chemicals) were selected as starting materials in this study, which have specific surface areas of 8.1 and $3.6 \mathrm{~m}^{2} / \mathrm{g}$, respectively. PVA with polymerization degree of 2000 and PVC with polymerization degree of 1020 were used as carbon source for pyrolysis. According to previous experimental studies of our group and based on literature, ${ }^{12), 17)}$ it is decided for all cases prior to coating operation, $\mathrm{ZnO}$ powder and either PVA or PVC were mixed with mass ratio $(\mathrm{ZnO} /$ polymer) of 1 until obtaining homogenous mixture, Under Ar gas with a flowing rate of $50 \mathrm{ml} / \mathrm{min}$, asreceived mixture was heated for $3 \mathrm{~h}$ at $650^{\circ} \mathrm{C}$ with a heating rate of $5^{\circ} \mathrm{C} / \mathrm{min}$.

Analytical characterization techniques of XRD (RIGAKU ${ }^{\mathrm{TM}}$, RINT 2000), SEM (FE-SEM: HITACHI ${ }^{\mathrm{TM}}$ S 4500) and TEM (JEOL ${ }^{\mathrm{TM}}$, JEM-1200 EX II) were used for phase analysis and morphology of as-coated powders. Specific surface area measurement was performed by the adsorption isotherm of nitrogen gas at 77K (BET: Bel Japan ${ }^{\mathrm{TM}}$, Belsorp mini). 


\section{Results and discussion}

3.1 Effect of initial powder properties on carbon coating $\mathrm{ZnO}-\mathrm{I}$ and $\mathrm{ZnO}-\mathrm{II}$ powders were coated with carbon by using PVA. In the observations of $\mathrm{ZnO}-\mathrm{I}$ after coating, the color turned to black, probably due to the formation of homogeneously coating film on the surface of powder. In the case of $\mathrm{ZnO}-\mathrm{II}$, however, it was possible to distinguish clearly the color as black and white. Since $\mathrm{ZnO}$-II powder has initially lower surface area, it may be concluded that homogeneous carbon coating is not always possible especially in case when the particles could not be wetted by low viscosity transient liquid during PVA pyrolysis.

\subsection{Effect of kind of polymer as carbon source}

In order to understand the effect of polymer on the formation of carbon coating film, carbon was coated on the surface of $\mathrm{ZnO}-\mathrm{I}$ by the pyrolysis of either PVA or PVC. In the case of PVA, after pyrolysis sample was found in powder form. After pyrolysis with PVC however, a cake-like sample structure was obtained. Strength of this cake was very low and it was easily pulverized.

After the pyrolysis of $\mathrm{ZnO}$ powders with PVA, an agglomeration tendency was detected among some of the powders. In the submitting report, ${ }^{18)}$ this behavior was also observed in both $\mathrm{ZnO}$ and $\mathrm{CaO}$ systems. Using a sieve (150 micron), the powders were separated into two fractions and the percentage of the mass remained on the sieve $(+150$ micron) agreed with agglomerated powders. The agglomeration decreased with increasing polymerization degree of PVA and the trend was same in the case of carbon-coated $\mathrm{ZnO}$ and $\mathrm{CaO}$ powders.

In this experimental work, though initial $\mathrm{ZnO}-\mathrm{I}$ powders were easily passed through under 150 micron, two fractions were observed after the coating of carbon by using PVA; that is, the fractions were calculated as $49.88 \%(+150$ micron $)$ and $50.12 \%$ ( -150 micron $)$. Hardness of individual particles with the +150 micron fraction was relatively higher than that of the cake obtained after the pyrolysis of PVC. In order to examine the amount of residual carbon in these carbon-coated samples, the oxidation of the samples was performed at $1000^{\circ} \mathrm{C}$ in air. The results have shown that the mass loss of agglomerated powders $(+150$ micron $)$ was larger than that of fine fraction $(-150$ micron $)$ giving the idea that agglomeration formation should be related to amount of carbon residue rather than sintering effect of $\mathrm{ZnO}$ particles. The values of specific surface area in all powder samples were summarized in Table. 1. As it can be followed from this table, the specific surface area of $\mathrm{ZnO}$ powders without carbon was smaller than that of carbon-coated samples. In the case of PVA, the carbon-coated sample with agglomerated (+150 micron) fraction was found to be higher surface area than those of the finer fraction $(-150$ micron $)$. Since the increase in the surface area is directly in relation with the amount of carbon in the coated sample, the increase from the value of 36.8 ( -150 micron) to $89.4 \mathrm{~m}^{2} / \mathrm{g}$ ( +150 micron $)$ is logical and harmonious with previous findings. In the case of PVC, however, the specific surface area of ZnO-I showed high value of $404.9 \mathrm{~m}^{2} / \mathrm{g}$ in comparison to the PVA case.

In Fig. 1, XRD patterns of ZnO-I powder before and after coating were shown. As it can be easily followed from this figure, diffraction peaks corresponding to hexagonal- $\mathrm{ZnO}$ were detected in all samples and no peaks of carbon were observed in carbon-coated samples possibly indicating that carbon formed on the surface of $\mathrm{ZnO}$ is amorphous.

TEM observations of carbon coated powders were performed in order to get more information about the structure
Table 1. Measured Specific Surface Area Values of Initial and AsCoated Powders

\begin{tabular}{|c|c|}
\hline Sample & $\begin{array}{c}\text { Specific Surface } \\
\text { Area } \\
\left(\mathrm{m}^{2} / \mathrm{g}\right)\end{array}$ \\
\hline ZnO-I & 8.1 \\
\hline ZnO-II & 3.6 \\
\hline $\begin{array}{c}\text { ZnO-I } \\
\text { (After Pyrolysis with PVA -150 micron) }\end{array}$ & 36.8 \\
\hline $\begin{array}{c}\text { ZnO-I } \\
\text { (After Pyrolysis with PVA +150 micron) }\end{array}$ & 89.4 \\
\hline $\begin{array}{c}\text { ZnO-I } \\
\text { (After Pyrolysis with PVC) }\end{array}$ & 404.9 \\
\hline ZnO+PVA 2000 (Compacted) -150 micron & 31,6 \\
\hline ZnO+PVA 2000 (Compacted) +150 micron & 84,6 \\
\hline
\end{tabular}

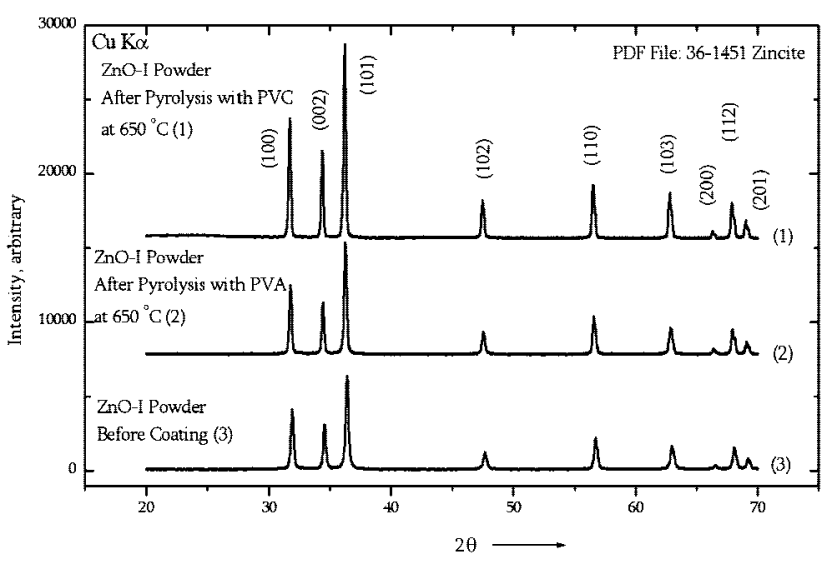

Fig. 1. $\mathrm{XRD}$ of initial and $\mathrm{C}$ coated $\mathrm{ZnO}$ powders.

of residual carbon deposition on the surface of powders. TEM micrographs of carbon-coated samples obtained by the pyrolysis of PVA and PVC are shown in Fig. 2. Figures 2 (a) and (b) show carbon-coated $\mathrm{ZnO}-\mathrm{I}$ prepared from -150 and + 150 micron powders, respectively. In the sample prepared from -150 micron powders (Fig. 2 (a)), the particles with the size of $20-100 \mathrm{~nm}$ can be easily observed. In the sample obtained from +150 micron powders (Fig. 2(b)), one can observe the agglomeration among the given powders. Relatively dark portion seen in this figure are $\mathrm{ZnO}$ particles with the size of around $50-100 \mathrm{~nm}$, and these particles were surrounded by carbon matrix seen in light gray tone. During overall TEM observations of the agglomerated powders, no direct sintering bond between $\mathrm{ZnO}$ particles were observed. Therefore, it is concluded that some $\mathrm{ZnO}$ particles were kept among these residual carbon structure during coating and it resulted as a formation of agglomerates in after coating structure. Figures 2 (c) and (d) are TEM micrographs of the carbon-coated $\mathrm{ZnO}-\mathrm{I}$ prepared by the pyrolysis of PVC. $\mathrm{ZnO}$ particles with needle-like shape can easily be seen from Fig. 2 (c). Although the formation mechanism of needle-like shape is not yet clear, in the right side of Fig. 2(d), the detailed structure of the residual $\mathrm{C}$ was observed in higher magnifica- 

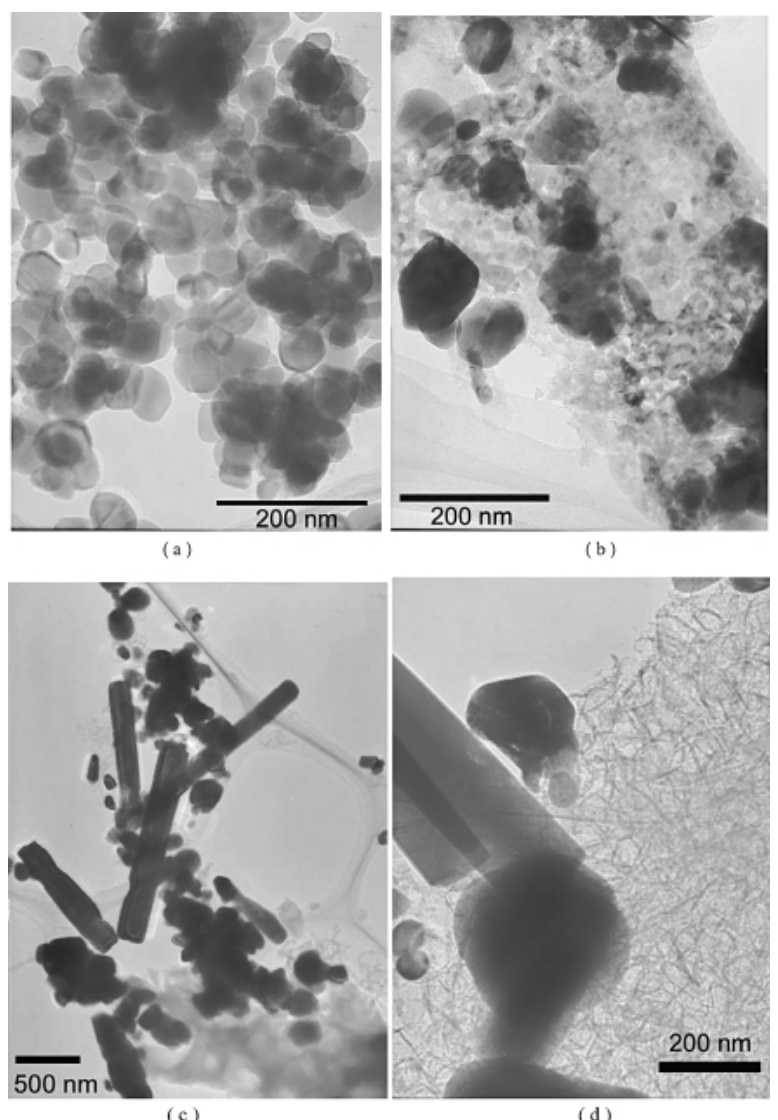

(c)

(d)

Fig. 2. TEM micrographs of $\mathrm{C}$ coated $\mathrm{ZnO}$ powders.

(a) ZnO-I after pyrolysis with PVA ( -150 micron), (b) $\mathrm{ZnO}-\mathrm{I}$ after pyrolysis with PVA (+150 micron), (c) ZnO-I after pyrolysis with PVC, general view, (d) ZnO-I after pyrolysis with PVC in higher magnification.

tion in addition to needle-like shape and spherical $\mathrm{ZnO}$ particle.

Figures $3(a)$ and (b) are TEM micrographs of comparative high magnification of residual carbon on the carbon-coated samples after the pyrolysis of PVA and PVC, respectively. The structure of residual carbon was apparently different; that is, while PVA pyrolysis can lead the formation of round shaped nanoporous carbon (Fig. 3 (a)), PVC pyrolysis resulted in the formation of fiber-bare like structure with nanometer size (Fig. 3(b)). The reason why the specific surface area of carbon-coated sample prepared by the pyrolysis of PVC was higher than those obtained by pyrolysis of PVA may be explained to be due to the formation of fiber-bare like shape in the structure.

3.3 Effect of particle-particle distance during polymer pyrolysis

All discussions so far were based on the coated powders that are prepared by pyrolysis of loose mixtures of $\mathrm{ZnO}$ and polymer powder blends. In order to see the effect of $\mathrm{ZnO}$ particleto-particle distance during pyrolysis, $\mathrm{ZnO}$ and PVA powder mixture was compacted in a rigid cylindrical die with $200 \mathrm{MPa}$ compaction pressure and coating was realized under same conditions. It is observed that, after the pyrolysis the compacted powders were returned into powder form. The powders, obtained after pyrolysis of the compact, showed higher agglomerated fraction $(+150$ micron, $58.5 \%)$ than the loose powder case $(+150$ micron, $49.88 \%)$. Microstructural inves-
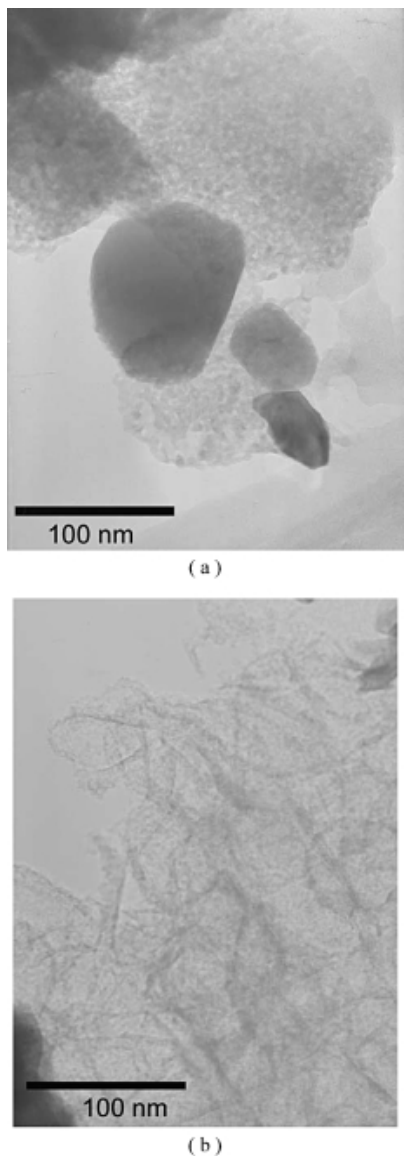

Fig. 3. High magnification TEM micrographs of observed carbon structure.

(a) Carbon source PVA, (b) Carbon source PVC.

tigations of these powders were performed by SEM and comparative micrographs were given in Figs. 4(a) and (b). Although every other parameter is kept constant, after pyrolysis appearances of compacted powders are quite different from appearance of the loose powder mixture. By effect of compaction pressure, it is obvious that, $\mathrm{ZnO}$ particles were packed together in surrounded PVA matrix prior to pyrolysis. Although there was no additional external force acting on the compact during pyrolysis, individual $\mathrm{ZnO}$ particles probably showed grouping or agglomeration tendency with the neighborhood particles. It is thought that compaction pressure was the driving force for this behavior by creating higher capillarity between the initial $\mathrm{ZnO}$ particles. The specific surface area values of the powders obtained by pyrolysis of the compacted mixture were found slightly to be lower than that of the loose powder mixture (Table. 1). That is harmonious with the observed grouping effect.

\section{Summary}

Although polymer pyrolysis method is relatively simple method for coating fine particles via carbon layer, homogeneous carbon coating is not always possible especially when the particles could not be wetted by low viscosity transient liquid during pyrolysis. Initial powder properties like high surface area and purity are important parameters for obtaining successfully $\mathrm{C}$ coated composite powders.

Based on carbon oxidation experiments and TEM observations, it is concluded that the specific reason for observed 


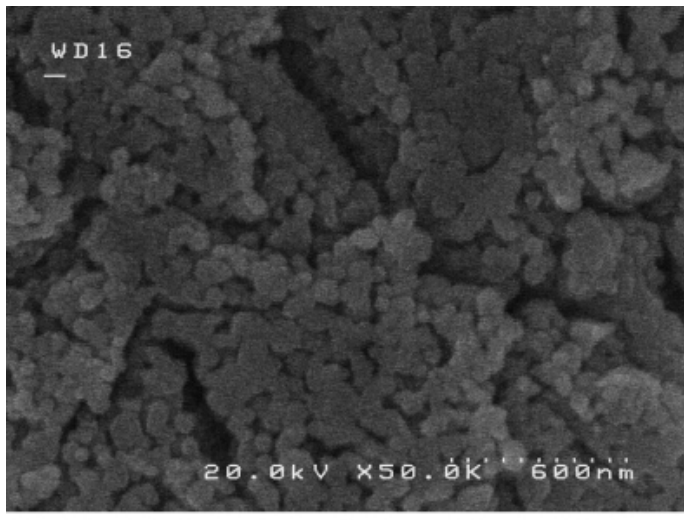

(a)

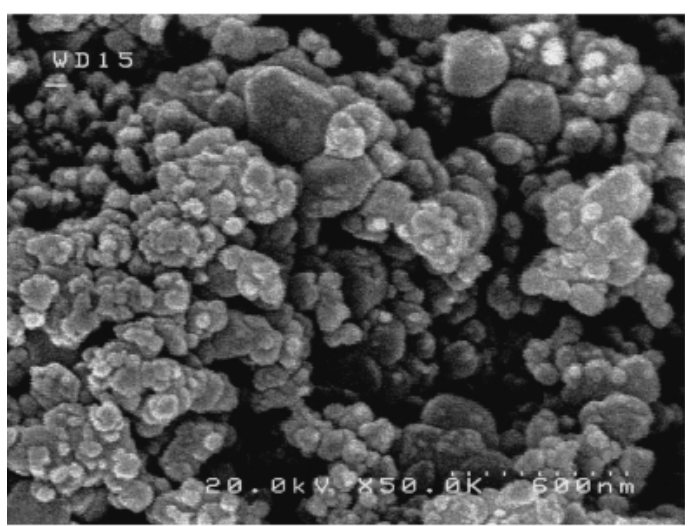

(b)

Fig. 4. Morphology of the $\mathrm{C}$ coated $\mathrm{ZnO}-\mathrm{I}$ powders via PVA pyrolysis.

(a) Loose powder mixture, (b) Compacted mixture.

agglomerates after PVA pyrolysis is related to nature of the carbon residue rather than sintering effect of $\mathrm{ZnO}$ particles. $\mathrm{ZnO}$ particles were kept among these residual carbon structure leading agglomerates. However, after pyrolysis with PVC, as a result of very high surface area carbon residue, cake formation was observed.

In the case of PVA, specific surface area of the carbon-coated $\mathrm{ZnO}$ powders for agglomerated ( +150 micron) and finer ( -150 micron) fractions were measured as $89.4 \mathrm{~m}^{2} / \mathrm{g}$ and $36.84 \mathrm{~m}^{2} / \mathrm{g}$, respectively. However, when PVC was selected as carbon source, the specific surface area of after coated powders was measured as $404.9 \mathrm{~m}^{2} / \mathrm{g}$.It is concluded by TEM observations that the difference comes from the formation of the different nanoporous carbon residues in the structures. Therefore, selection of polymeric precursor as a carbon source is very important for final properties of the carbon coated composite powders.

It is also found out that, physical distance among coated particles during pyrolysis are also important parameter which affects the final morphology and remained carbon amount in the structure.

\section{References}

1) Sherman, A. J., Smith, G. and Baker, D., "Advances in Powder Metallurgy and Particulate Materials” (2001) pp. 1578-1588.

2) Li, G.-J, Huang, X.-X., Guo, J.-K. and Chen. D.-M., Ceramics International, Vol. 28 pp. 623-626 (2002).

3) Capus, J. M., Metal Powder Report, Vol. 53, pp. 30-31 (1998).

4) Özkal, B., Upadhyaya, A., Öveçoğlu, M. L. and German, R. M., 2nd National Powder Metallurgy Conference Proceedings Book, Turkish Powder Metallurgy Association, Ankara, Ed. by Saritas, S. (1999) pp. 185-191.

5) McEnaney, B., "Carbon Materials for Advanced Technologies," Ed. by Burchell, T. D., Pergamon, The Netherlands (1999) pp. 1-29.

6) Shiflett, M. B. and Foley, H. C., Science, Vol. 285, pp. 1902-1905 (1999).

7) Acharya, M. and Foley, H. C., J. Membr. Sci., Vol. 161, pp. 1-5 (1999).

8) Soffer, A., Koresh, J. E. and Saggy, U.S. Patent 4, 685, 940 (1987).

9) Liu, P. K. T., Gallaher, G. R, Wu, J. C. S., U.S. Patent 5, 262, 198 (1993).

10) Gilman, J. W., American Chemical Society, ACS Syposium series 599 (1994) pp. 161-185.

11) Lu, J., Ma, S., Gao, J., Freitas, J. C. C. and Bonagamba, T. J., Jour. App Polymer Sci., Vol. 90, pp. 3252-3259 (2003).

12) Inagaki, M., Miura, H. and Konno, H., J. Eur. Ceram. Soc., Vol. 18, pp. 1011-1015 (1998).

13) Inagaki, M., Fujita, K., Takeuchi, Y., Oshitai, K., Iwata, H. and Konno, H., Carbon, Vol. 39, pp. 921-929 (2001).

14) Inagaki, M., Hirose, H., Matsunaga, T., Tsumura, T. and Toyoda, M., Carbon, Vol. 41, pp. 2619-2624 (2003).

15) Krivoruchko, O. P., Maksimova, N. I., Zaikovskii, V. I. and Salanov, A. N., Carbon, Vol. 38, pp. 1075-1082 (2000).

16) Lee, H.-Y., Baek, J.-K., Jang, S.-W., Lee, S.-M., Hong, S.-T., Lee, K.-Y. and Kim, M.-H., Journal of Power Sources, Vol. 101, pp. 206-212 (2001),

17) Özkal, B., Jiang, W., Yamamoto, O., Fuda, K. and Nakagawa, Z., The 42th Symp Basic Science of Ceramics Abstract Book, Ceramic Society of Japan (2004) pp. 12-13.

18) Work Submitted to JMS, Preparation and Characterization of Carbon-Coated $\mathrm{ZnO}$ and $\mathrm{CaO}$ Powders by Pyrolysis of PVA. 